\title{
Medical tourism facilitators: Patterns of service differentiation
}

Journal of Vacation Marketing 17(3) 165-183

(C) The Author(s) 2011

Reprints and permission:

sagepub.co.uk/journalsPermissions.nav DOI: $10.1177 / 13567667 \mid 1409 / 81$

jvm.sagepub.com

\author{
Lydia L. Gan and James R. Frederick \\ University of North Carolina at Pembroke, USA
}

\begin{abstract}
This article studies the nature of differentiation in the market for medical tourism facilitators in the USA. Medical tourism facilitators in the USA resemble a monopolistically competitive industry. They choose to differentiate their services in several ways, including by the scope of countries and hospitals which they use, the scope of the treatments in which they specialize, the extent of involvement of medical professionals in the company, and the kinds of ancillary services they offer. The authors perform an exploratory study of the differentiation among 46 such firms. Using principal-components analysis, they detect three components: an emphasis on providing a broad selection of destinations, an emphasis on physician's concerns, and an emphasis on the travel aspects of medical tourism. Cluster analysis separates the firms' profiles into six types.
\end{abstract}

Keywords

cluster analysis, differentiation, healthcare tourism, medical tourism, medical tourism agents, principal component analysis

\section{Introduction}

An estimate for 2007 put the number of Americans who travel abroad for medical care at 750,000 (Baliga, 2006; Deloitte, 2008). This phenomenon is known as 'medical tourism,' which we define as 'residents seeking medical, dental, and cosmetic surgeries (both elective and non-elective) from healthcare providers outside their home countries.' Although this number is still a small fraction of all US consumers who could benefit from foreign health care, it is expected to grow as (1) the ease of access to healthcare in the USA declines and the cost of US healthcare continues to rise, (2) the number of those uninsured increases to around 46.3 million (DeNavas-Walt et al., 2009) as less coverage is provided by the insurance companies and more employers find that they cannot afford to provide healthcare for their employees, and (3) the baby boomers age. The market for medical tourism is projected to explode from threequarter million travelers in 2007 to 23 million by 2017 , at which time spending on medical tourism is expected to reach US\$79.5 billion per year (Deloitte, 2009).

\section{The four mode model of medical tourism}

In the USA, the exponential growth in the market for medical tourism is rapidly changing the way major industry players such as domestic medical tourism facilitators (DMTF), foreign healthcare providers (FHP), domestic insurance companies (DIC), domestic employers (DE), domestic healthcare providers (DHP), and foreign medical tourism facilitators (FMTF) are interacting with each other to form partnerships and to compete for business both within and outside the USA.

Corresponding author:

Lydia L Gan, Department of Economics, Finance, and Decision Sciences, School of Business, University of North Carolina at Pembroke, P O Box 1510, Pembroke, NC 28372-I5I0, USA

Email: lydia.gan@uncp.edu 


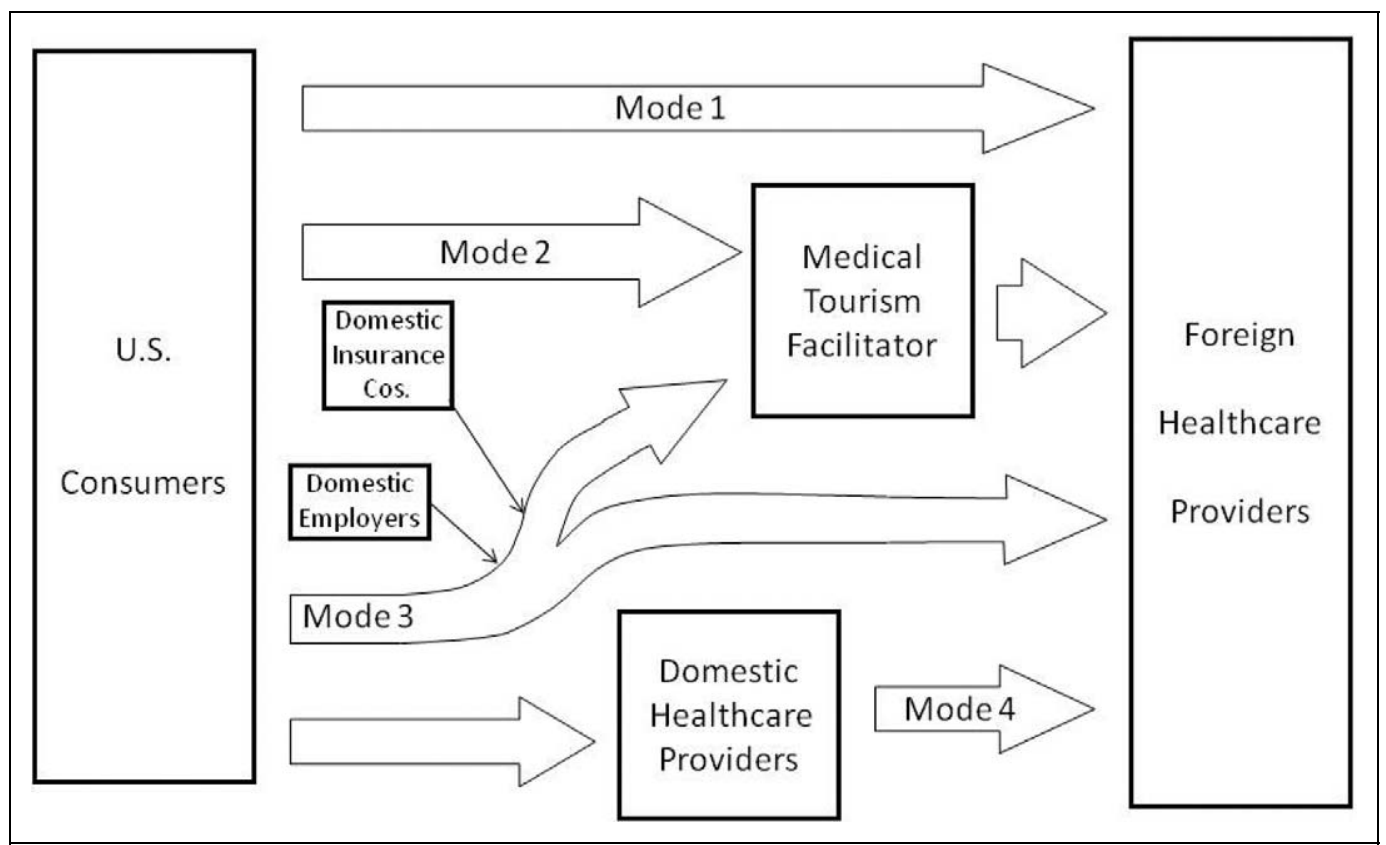

Figure I. Four Mode Model

The interaction of these key players can be captured in the following four transactional modes of medical tourism, as summarized in Figure 1.

Mode 1: Direct medical tourism. Consumers who use this mode are familiar with a foreign hospital and make their own arrangements for travel and medical treatment. This is the simplest and earliest mode of medical tourism.

Mode 2: Medical tourism arranged by medical tourism facilitators (MTFs). This mode represents consumers who use the services of agencies that specialize in locating suitable foreign hospitals and arranging treatment, transportation, and lodging during recuperation.

Mode 3: Medical tourism induced by US health plans or by US employers. As the availability of medical care in foreign hospitals has become more widely recognized and in an effort to contain cost, some employers and insurance companies have started to provide incentives for covered employees to seek medical care outside the USA. Similarly, some managed-care health plans have included foreign hospitals on their lists of approved providers as a way to reduce costs.

Mode 4: Medical tourism encouraged by US healthcare providers (DHP). This is an extension of the common practice of hospitals outsourcing medical services. At the time of writing, there are only a small number of anecdotal instances of this occurring, but as more US hospitals partner with foreign hospitals, as after care is gaining its well-deserved attention in medical tourism, and as consumers become more accustomed to these partnerships, this mode may grow in importance. Some US healthcare providers with international presence are already sharing their management protocols with FHPs (H\&HN, 2004). For instance, Johns Hopkins has developed consulting and referral relationships with FHPs in India and Singapore. These arrangements generate revenues through fees, and occasionally may result in patient referrals.

This article will focus on Mode 2 - the domestic medical tourism facilitator (DMTF) industry. Specifically, the purpose of this article is to show that the DMTF industry is characterized by differentiation in the nature of the services provided to consumers, but that patterns do exist amid the diversity.

\section{Literature review}

The major 'push' factors driving medical tourism include the convenience of using the internet to gather information (Henderson, 2004), the availability of skilled labor abroad, the fact that globalization has facilitated the ease of travel between countries (Carrera and Bridges, 2006), and the emergence of low cost telecommunication and 
economy air travel (Turner, 2007) (see Table 1). In the USA, there are institutional 'push' factors that drive medical tourism. These are favorable regulation (Bramstedt and $\mathrm{Xu}, 2007$; Palvia, 2007) such as West Virginia and Colorado House Bills (Canterbury et al., 2007; Ellem et al., 2008; Rodighiero et al., 2008; Swalm and Lundberg, 2007). Inducements by the third party healthcare payment system in the form of bonuses and cash incentives offered by employers and insurance companies constitute another aspect of institutional factor. For instance, in the historic case of Blue Ridge Paper Products, Inc., the incentives the company offered its employees if they chose to have elective surgeries at the PPOapproved hospitals in India included the employees' airfares and extra sick leave in addition to a US\$10,000 bonus (McLean, 2007; Milstein and Smith, 2006). Similarly, some managed-care health plans have included foreign hospitals on their lists of approved providers as a way to reduce costs. For instance, the Blue Cross Blue Shield of California has recently provided discounted health plans that provide incentives for individuals to receive most of their care in Mexico (Vequist and Valdez, 2008). Similarly, in early 2009, Blue Cross Blue Shield of South Carolina formed its first international partnership with Bumrungrad Hospital in Thailand (Vitalis and Milton, 2009). These 'push' factors have all made medical tourism more feasible.

Several 'pull' factors also drive medical tourism. The majority of the literature reviews focus on the sizable cost savings (AMA-OMSS, 2007; Demicco and Cetron, 2006; Forgione and Smith, 2007; Mattoo and Rathindran, 2006; Turner, 2007). Just as high cost does not assure high quality, low cost does not necessarily imply low quality. Hospitals in emerging economies benefit from lower bureaucratic and administrative fees (AMA-OMSS, 2007, Horowitz, 2008); lower labor and training costs (Carabello, 2008; Horowitz and Rosensweig, 2007; Mattoo and Rathindran, 2006; Turner, 2007), less stringent regulatory environments (AMA-OMSS, 2007; Carabello, 2008; Horowitz, 2008), lower malpractice insurance or litigation costs (AMA-OMSS, 2007; Carabello, 2008; Forgione and Smith, 2007), less or no involvement of third-party payers (Carabello, 2008; Herrick, 2007), and lower pharmaceutical charges (Forgione and Smith, 2007), allowing them to provide health care at lower monetary costs. For instance, a heart bypass surgery (CABG) that costs US $\$ 70,000$ to US $\$ 133,000$ in the USA might only cost US $\$ 8,639$ (includes medical costs, airfare and hotel accommodation) in a high-tech hospital in India using western-trained surgeons, which constitutes a 92\% saving (see Table 2). Gastric bypass surgery in the USA can cost from US $\$ 35,000$ to US $\$ 52,000$, whereas it can be done for around US\$11,000 (all inclusive) in India or South Korea, which represents a saving of $75 \%$.

Other studies have noted other motivating 'pull' factors that drive the US consumers seeking treatments abroad, such as minimal waiting lists (Bies and Zacharia, 2007; Connell, 2006; Horowitz and Rosensweig, 2008), more personalized care (Demicco and Cetron, 2006; Fried and Harris, 2007), availability of treatments (Brady, 2007; Demicco and Cetron, 2006), or greater privacy and confidentiality (Fried and Harris, 2007; Horowitz and Rosensweig, 2008).

In selecting a particular country destination, key country 'pull' variables considered by medical tourists are political concerns (Bookman and Bookman, 2007; Dhariwal, 2005; Palvia, 2007), social and cultural compatibility (Seddighi et al., 2001; Uysal and Crompton, 1984), or the freedom from disasters (Fernandez et al., 2002; Huan et al., 2004), and along with them bioethical legislations such as tourism involving stem cell, fertility, abortion, and euthanasia (Glinos et al., 2010).

Some of the major 'pull' factors that attract consumers to a particular destination hospital are: (1) highly acclaimed international accreditation and reputation (Berkowitz and Flexner, 1981; Mattoo and Rathindran, 2006); (2) quality of care in terms of surgical outcomes and high nurse-patient ratios (Berkowitz and Flexner, 1981; Demicco and Cetron, 2006; Higgins, 2007; Lane and Lindquist, 1988); (3) the credentials and training of foreign physicians (Mattoo and Rathindran, 2006); (4) advanced medical technology and equipment (Demicco and Cetron, 2006); and (5) HIPAA compliance (Forgione and Smith, 2007; Marlowe and Sullivan, 2007).

The existing literature on the demographic profile and socioeconomic status of potential consumers who participate in medical tourism is seriously lacking (Lunt and Carrera, 2010). Many mentioned the high proportion of uninsured as potential medical tourists (Higgins, 2007; Horowitz and Rosensweig, 2008), others deduced they are likely to be middle-income (Horowitz and Rosensweig, 2008; Milstein and Smith, 2006) and middle-aged (Lunt and Carrera, 2010; Milstein and Smith, 2006). A recent study by Gan and Frederick (2011) has shown that potential medical tourists who are motivated by 
Table I. Summary of literature review on medical tourism

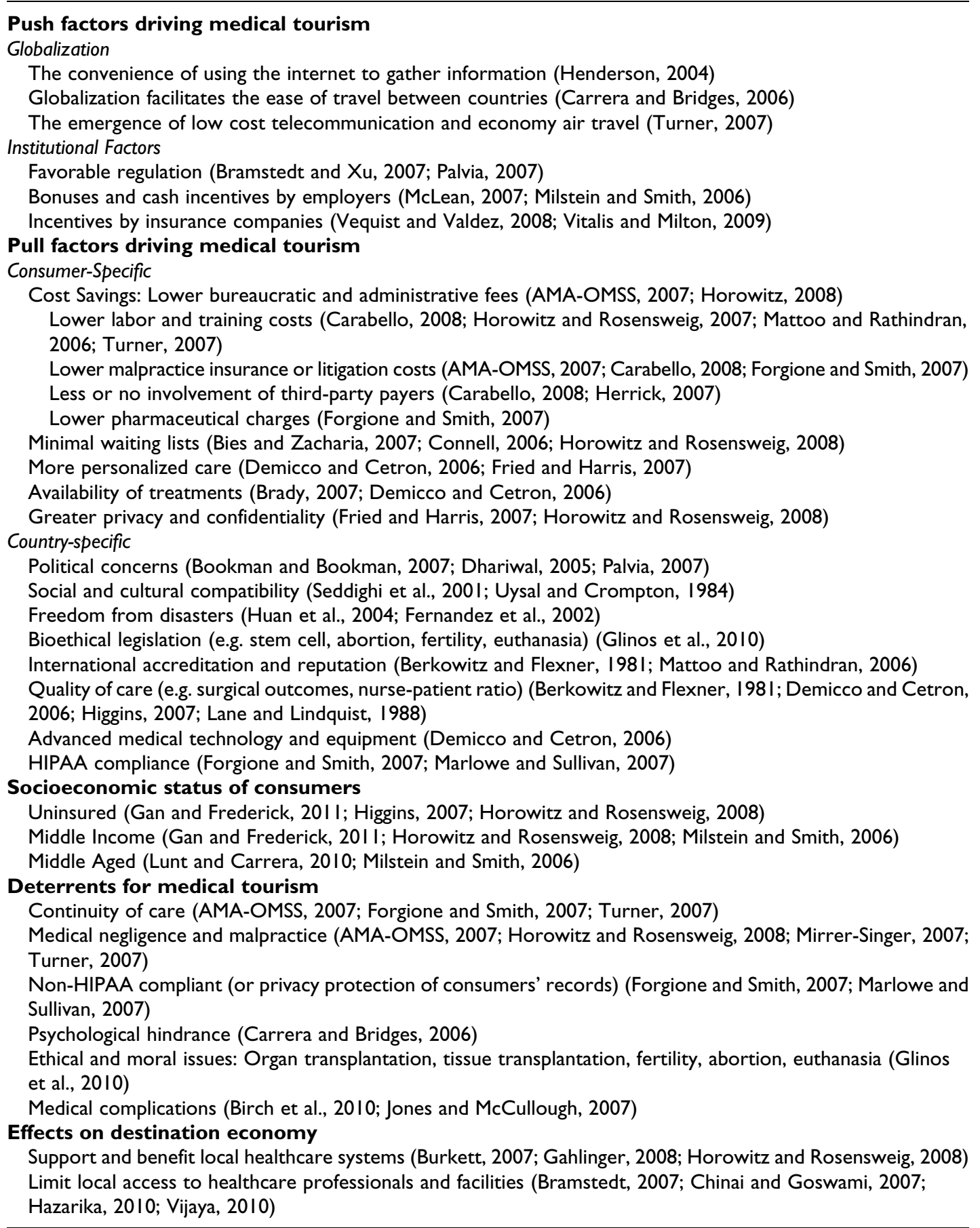

economic reasons to travel for treatment are likely to be uninsured and middle-income earners.

Just as there are motivations, there are deterrents to consumers in the fast growing medical tourism industry as well. The question of continuity of care remains a legitimate issue for potential consumers who contemplate medical tourism (AMA-OMSS, 2007; Forgione and
Smith, 2007; Turner 2007). Some argued that complications, side-effects, and post-operative care can defeat the cost-saving for consumers seeking care abroad. Medical negligence and malpractice are another major concern for potential consumers (AMA-OMSS, 2007; Horowitz and Rosensweig, 2008; Mirrer-Singer, 2007; Turner 2007). Further, unresolved fiduciary 


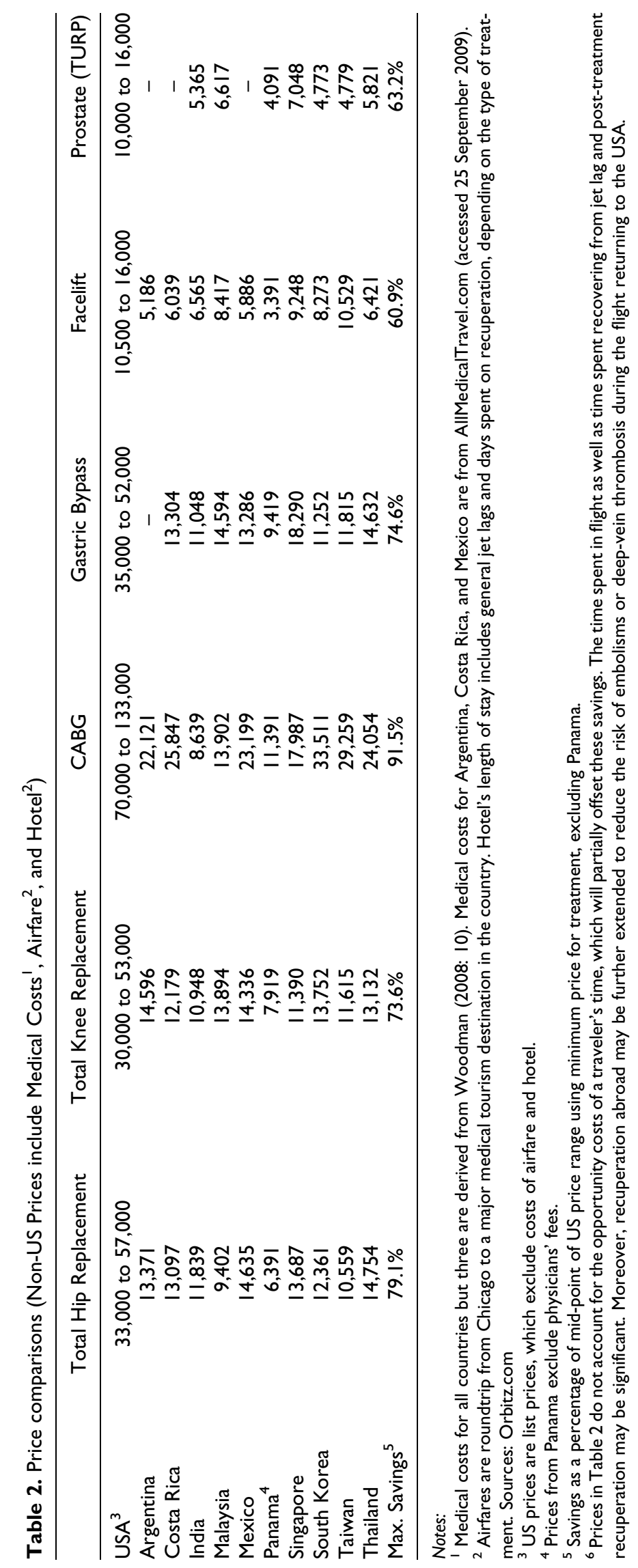


responsibility can include issues such as whether the employers (or the medical tourism facilitators) are free from liability in case of malpractice, and whether the foreign hospitals are HIPAA compliant, thus ensuring the privacy protection of consumers' records (Forgione and Smith, 2007; Marlowe and Sullivan, 2007). Closely related are ethical and moral issues that revolve around medical complications (Birch et al., 2010; Jones and McCullough, 2007), organ transplantation, tissue transplantation, fertility, abortion, and euthanasia (Glinos et al., 2010) that can deter some from seeking medical treatment abroad. Finally, one psychological hindrance is simply the affinity to one's local environment in terms of medical needs and quality of care (Carrera and Bridges, 2006).

Other questions connected with the destination economies are greater social issues, such as the universal right to health. For instance, are the 'affluent foreign' patients absorbing the healthcare resource from the local communities, which are often less affluent and less able to afford quality healthcare (Bramstedt, 2006; Chinai and Goswami, 2007; Hazarika, 2010; Vijaya, 2010)? Others argued that the revenues earned from medical tourism can be reinvested into the destination economies to attract better trained physicians as well as to better serve both the foreign and the local patients who otherwise would have limited access to modern medical facilities and services (Burkett, 2007; Gahlinger, 2008; Horowitz and Rosensweig, 2008).

\section{Domestic medical tourism facilitator (DMTF)}

One of the fastest growing sectors in the industry is the domestic medical tourism facilitators (DMTFs) or 'agents'. These are the middlemen who connect a potential consumer with a foreign healthcare provider (FHP) for the purpose of arranging a medical, dental or a cosmetic treatment outside the consumer's home country. In addition to matching a patient with an appropriate FHP, the DMTFs add value to their services by arranging the entire process of pre- and post-care treatments, the transfer of medical records, travel arrangements, and in some cases arranging for a personal manager or a translator, or even scheduling tours in the destination country.

Many small, new companies such as insurance brokers, healthcare solutions companies, risk management companies, and companies specializing in after-care are beginning to emerge to provide supporting services to the medical tourism industry. The DMTFs especially are aided by these support-service firms, which are defined by their niche services. Some examples of these firms are internet portal companies such as Medical Nomad (http://www.medicalnomad.com) and Planetmedix (http://www.planetmedix.com) that centralize information and facilitate the search for DMTFs and FHPs, and companies that specialize in after-care services such as Homewatch International, Inc.

\section{DMTF - A monopolistic competitive market}

We estimate the number of DMTFs and their support-service firms currently operating in the USA to be less than 100, and most DMTFs surveyed for this study were established after the year 2007. There are many firms, none of which appears to be dominant. The barriers to entry are low, and the firms possess more information than the consumers, thus they may have some ability to raise prices without losing all of their sales (especially through advertising by more established DMTFs). Most of all, there is substantial differentiation of services among these firms. The current DMTF industry thus fits the conditions of a monopolistically competitive industry rather well. A review of the firms' websites further revealed their differentiation strategies in areas such as the countries and hospitals they utilize, the kinds of services they provide, and in their indicators of quality.

\section{Differentiation strategies}

When an entrepreneur thinks of creating a DMTF, the entrepreneur must decide how to market the new firm to potential clients and to set the new firm apart from the competitors in the consumer's mind. Entrepreneurs' creativity has led to a variety of differentiation strategies. Some of the ways firms differ from each other are seen in the variety of services offered, the different ways they instill trust, and in the ways they project themselves to consumers on their websites. Each entrepreneur chooses strategies that reflect the entrepreneur's own strengths. For example, a team that includes a physician and a travel agent would choose strategies that reflect those strengths, whereas a small one-woman firm is likely to specialize in one destination hospital.

The analysis of the DMTFs' websites shows this differentiation. In terms of the services 
offered, some deal with FHPs in a single country, while others offer a wide variety of countries and hospitals to which they refer their potential consumers. Similarly, there is much variation in the nature of the services offered by DMTFs. On the low end, some DMTFs do little more than provide information about foreign hospitals and arranging air transportation, relying on the hospitals to provide most of the services. On the other hand, well established, comprehensive DMTFs arrange to get visas, see that medical consultations are undertaken prior to travel, coordinate communication between doctors in the USA and those abroad, have medical records transmitted, arrange for a companion to accompany the patient (in some cases even hire a personal nurse from care giver services to monitor patients), find pleasant accommodations for the time spent recuperating in the destination country, and arrange for follow-up care upon return to the home country.

\section{Destination countries}

The primary function of DMTFs is to refer potential consumers to foreign healthcare providers in destination countries. On the part of DMTFs, this will involve networking or partnering with a few FHPs in destination countries and gaining basic travel information (e.g. exchange rates, visa requirements, hotel accommodation, weather, customs) about these countries. Some narrowly-focused DMFTs work with only one or two foreign hospitals in a single country, such as Costa Rican Medical Care (http://www.costaricanmedicalcare.com) or Aesthetics Abroad (http://aestheticsabroad.com/en_home.php), or with a small number of foreign hospitals in a single country, such as IndUShealth (http:// www.indushealth.com) and European Medical Tourist (http://www.europeanmedicaltourist.com), while others work with a long list of foreign hospitals in many countries. For instance, Placid Way (http://www.placidway.com) works with hospitals in more than 50 countries.

Our review of DMTFs' websites shows that the five most popular country destinations referred by the DMTFs are: India, Thailand, Singapore, Mexico, and Costa Rica. Other emerging countries popular with US medical tourists are Malaysia, the Philippines, South Korea, and Taiwan in Asia; Brazil, Columbia, Argentina, Guatemala, and El Salvador among Latin American countries; Turkey, Jordan, United Arab Emirates, and South Africa in the Middle East.

\section{Destination hospitals}

Just as DMTFs differentiate themselves in the number of countries they refer their potential consumers, some DMTFs differentiate by specializing in only one or two hospitals, while some claim to send patients to hundreds of hospitals. Regardless of the number of hospitals used, it is important to explicitly name the hospitals DMTFs refer their consumers to on their websites mainly to increase consumers' interest in the firms. While some firms provide the names of the hospitals and doctors with which they work, some prefer to withhold the names of hospitals, doctors, or in some cases even the countries they use. For instance, Medcentrek (http://www.medcentrek.com) identifies three countries, but does not identify any hospitals or doctors. In selecting a particular hospital, consumers can easily find whether a hospital has highly acclaimed international accreditation and a good reputation (Mattoo and Rathindran, 2006). Harder to find, but nonetheless important to consumers, is hospital-related information such as (1) quality of care (e.g. process and surgical outcomes, nursepatient ratio) (Berkowitz and Flexner, 1981; Demicco and Cetron, 2006; Higgins, 2007; Lane and Lindquist, 1988), (2) credentials and training of foreign physicians (Mattoo and Rathindran, 2006), (3) advanced medical technology and equipment (Demicco and Cetron, 2006), and (4) whether the hospital is HIPAA-compliant (Marlowe and Sullivan, 2007; Forgione and Smith, 2007). Such information may not be readily available on the hospital websites, even if the hospitals are identified. DMTFs who have visited the destination hospitals and conducted their own research are more likely to add value to consumers by having such knowledge.

\section{Types of treatment}

The types of treatment or procedure typically advertised by DMTFs on their websites can be classified under five broad categories: (a) medical, such as coronary artery bypass graft (CABG), and orthopedic surgery, such as knee or hip replacement; (b) weight-loss procedures, such as gastric bypass and lap band; (c) cosmetic or plastic surgery, such as facelift and breast augmentation; (b) dental, such as crowns, implants, and root canals; and (e) vision, such as LASIK.

The respective procedures popularly sought by medical tourists among the popular country destinations named above are as follows (Rosenthal, 2009): India is known for its 
orthopedic surgery (especially in knee resurfacing), and cardiac care; Singapore for its cancer treatment, spinal surgery, and transplants; Thailand for its orthopedic, cosmetic, and cardiac procedures. Due to the proximity to the USA, Mexico is conveniently located and well known for its dental work; and Costa Rica for its orthopedic, spinal, liposuction, and other cosmetic procedures.

\section{Quality indicators}

Some DMTFs advertise a number of quality indicators to assure potential consumers of the quality of their services, and ultimately to differentiate themselves. These quality indicators are their partnership with insurance companies or employers, their exclusive dealings with JCIaccredited or US affiliated foreign hospitals, the medical qualifications of their staff, and Better Business Bureau (BBB) accreditation.

\section{Strategic partnerships}

It is common for DMTFs to form partnerships with key industry players so as to create startto-finish experience for potential patients and allow value to be built at each step along a consumer's medical journey. Many DMTFs engage in strategic partnering with third-party payers or domestic insurance companies (DICs) and US or domestic employers (DEs). Examples of such strategic partnerships are the relationship between WorldMed Assist and Swiss Re, and the agreement between Companion Global Healthcare and BasicPlus Health Insurance (Zinkewicz, 2008). Taking advantage of lower labor and transaction costs, a few DMTFs may also partner with foreign medical tourism facilitators (FMTF) or foreign travel agencies to have a better access to the FHPs, foreign hotels as well as to gain a better knowledge of the local culture and vacation spots. The partnerships considered in this article are the ones between DMTFs and insurance companies or US employers.

A partnership between a DMTF and a DE or a DIC can be mutually beneficial. The DMTF can increase its leverage by gaining access to the pool of potential consumers that is provided by the DE or the DIC. It also gains an implicit stamp of approval from the DE or the DIC. Since there is a chance that a DE or a DIC could be sued as a result of an unfortunate outcome abroad (tort action against the FHP may be difficult because of differences in foreign legal systems), a DE or DIC needs to investigate the DMTF and the FHPs with which it deals. So, winning the approval of a DE or a DIC would be a signal of quality for a DMTF. Consumers will see this as an important differentiating feature when choosing a DMTF. On the other hand, a greater use of medical tourism by insured clients or workers would reduce costs of providing goodquality health care (assuming lower costs with comparable or better quality of care) on the parts of DEs and DICs.

\section{Exclusively $\mathrm{JCl}$-accredited hospitals}

Foreign healthcare providers (FHPs) are the final destinations for the medical travelers in their medical journey. Those FHPs that usually cater to international patients, including Americans, demonstrate their quality level by having western-trained doctors, by having accreditation by international bodies such as the Joint Commission International (JCI - an arm of the body that accredits most US hospitals in an attempt to improve safety and quality of care) or International Organization for Standardization (ISO), or by having partnerships with US affiliated hospitals. US affiliated hospitals will allow US consumers to feel more comfortable with opportunities for post-surgery services upon their return home. As a way to differentiate themselves, some higher-end DMTFs refer their potential consumers exclusively to JCI-accredited or ISO-certified or US affiliated hospitals.

A sample list of FHP destinations popular among medical tourists is shown in Table 3 . The hospitals on this list were selected to be representative of JCI-accredited hospitals in countries that are major destination countries for US medical tourists and which highlight various types of ownership and affiliations with US hospitals. These hospitals can be further divided into four broad categories: (1) US hospital-affiliated, such as Wockhardt Hospitals Group in India (affiliated with Harvard Medical International), and Anadolu Medical Center in Turkey (affiliated with Johns Hopkins International); (2) private and independent hospitals which may be: (a) religious-based or not-for-profit hospitals such as Christus Muguerza Group in Mexico or Penang Adventist Hospital in Malaysia, or (b) for-profit hospitals such as The Specialty Hospital in Jordan, Hospital Clinica Biblica in Costa Rica, and Bumrungrad Hospital in Thailand; (3) a chain of hospitals such as Apollo Hospitals Group in India, Acibadem Hospitals Group in Turkey, and Singhealth Group 
Table 3. Popular destination of foreign healthcare providers

\begin{tabular}{|c|c|}
\hline Foreign Hospitals & Type of Hospital \\
\hline \multicolumn{2}{|l|}{ I) Asia: India } \\
\hline $\begin{array}{l}\text { Fortis Escorts Heart Institute } \\
\text { Apollo hospitals Group }\end{array}$ & $\begin{array}{l}\text { Part of a privately owned chain of hospitals } \\
\text { A privately owned chain of hospitals }\end{array}$ \\
\hline Wockhardt Hospitals Group & $\begin{array}{l}\text { A privately owned chain of hospitals (affiliated with US-based Harvard } \\
\text { Medical International) }\end{array}$ \\
\hline \multicolumn{2}{|r|}{ 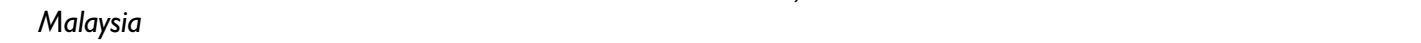 } \\
\hline Pantai Holdings Berhad & For-profit private hospital \\
\hline Penang Adventist Hospital & $\begin{array}{l}\text { Part of Adventist Health System, a chain of US-affiliated, religious-based } \\
\text { private hospitals }\end{array}$ \\
\hline $\begin{array}{l}\text { Prince Court Medical Centre } \\
\text { Singapore }\end{array}$ & For-profit private hospital \\
\hline $\begin{array}{l}\text { Johns Hopkins Singapore Interna- } \\
\text { tional Medical Centre }\end{array}$ & US-affiliated hospital (Johns Hopkins International) \\
\hline National Healthcare Group & Chain of public hospitals \\
\hline Parkway Health Group & Chain of private hospitals \\
\hline Raffles Medical Group & For-profit private hospital \\
\hline $\begin{array}{l}\text { SingHealth Group } \\
\text { Thailand }\end{array}$ & Chain of public hospitals \\
\hline Bumrungrad International & For-profit private hospital \\
\hline Samitivej group of Hospitals & Consortium of private hospitals \\
\hline $\begin{array}{l}\text { I) Central and South America: } \\
\text { Costa Rica }\end{array}$ & $\begin{array}{l}\text { Part of International Hospital Corporation, a chain of US-affiliated, for- } \\
\text { profit private hospitals }\end{array}$ \\
\hline Hospital CIMA, San Jose & $\begin{array}{l}\text { For-profit private hospital (affiliated with Mount Sinai Hospital, Florida, and } \\
\text { Tulane Medical Center, New Orleans) }\end{array}$ \\
\hline \multicolumn{2}{|l|}{$\begin{array}{l}\text { Hospital Clinica Biblica } \\
\text { Mexico }\end{array}$} \\
\hline $\begin{array}{l}\text { Christus Muguerza Group } \\
\text { Hospital San José Tec de, } \\
\text { Monterrey }\end{array}$ & $\begin{array}{l}\text { Religious-based group of private hospitals } \\
\text { For-profit private hospital }\end{array}$ \\
\hline I) The Middle East: Jordan & \\
\hline Al - Essra Hospital & For-profit private hospital \\
\hline $\begin{array}{l}\text { King Hussein Cancer Center } \\
\text { Turkey }\end{array}$ & For-profit private hospital \\
\hline Acibadem Hospital Group & Chain of private hospitals \\
\hline $\begin{array}{l}\text { Anadolu Medical Center } \\
\text { United Arab Emirates }\end{array}$ & US-affiliated private hospital (Johns Hopkins International) \\
\hline American Hospital, Dubai & For-profit private hospital \\
\hline University Hospital, Dubai & $\begin{array}{l}\text { University research hospital; US affiliated private hospital (Harvard Medical } \\
\text { International) }\end{array}$ \\
\hline
\end{tabular}

Source: Review of the hospitals' websites and some annual reports of the hospitals by the authors.

in Singapore; and finally (4) university research or teaching hospitals such as the University Hospital (also affiliated with Harvard Medical International) in Dubai. The hospitals listed under categories (3) and (4) can be either publicly or privately owned, for-profit or not-for-profit type.

In addition to the JCI-accreditation standards, there are notable accreditation standards outside the USA such as International Society for Quality and Safety in Healthcare (IsQua), Trent Accreditation Scheme (UK), the Accreditation Canada International (ACI), and Australian Council on Healthcare Standards (ACHS). However, in order to apply a standard quality indicator for DMTFs in reference to the hospitals to which they refer their consumers, we restrict the accreditation of hospital in our data collection to only JCI accreditation, US affiliation or ISO certification.

\section{Physician on staff}

Having a medical doctor (MD) as a founder or on the top-level management team of the company could be considered an indicator of quality. For instance, both IndUShealth and Satori World Medical have physicians and nurses on their staffs and Global Med Network, a DMTF based in Michigan was founded by a group of physicians. Others, such as One World Health Care, explicitly acknowledge having no medical 
expertise. Becoming a high-end, comprehensive DMTF requires having high quality resources, especially qualified staff with some medical knowledge. After the initial contact by potential patients, the firms usually request detailed medical information and ask for medical records from the patient's doctor in the USA. Ideally, this information would be reviewed by competent staff before a foreign hospital and doctor are recommended. At a minimum, a DMTF should have a US board-certified physician to review the data before a recommendation for treatment is made and the price for the procedure quoted. It is not unusual for some doctors to earn licenses in more than one country, thus allowing them to have hospital admitting privileges in more than one country (Smith and Forgione, 2008). In this context, US physicians who are foreign-born have some advantages when it comes to medical tourism - especially if they earn their medical degree and practice in the USA while keeping their medical licenses in their home country.

\section{BBB accreditation}

Some of the DMTFs use recognition by the Better Business Bureau on their websites in an attempt to signal quality to the consumers. Membership in the BBB by itself does nothing to improve quality, but low-quality firms are less likely to become members because of the costs of the BBB's complaint-resolution process.

\section{Ancillary services}

Another way that DMTFs differentiate themselves from each other is by offering various types of ancillary services to potential consumers. These ancillary services include coordinating of pre- and post-care, the assistance of a case manager, the provision of optional tour and spa packages, the option to choose from a variety of insurance types, and treatment-related educational information on the websites.

The firms may coordinate varying degrees of medical support services known as pre- and postcare to address the issue of continuity of care. They usually include facilitating communications between the consumer's US physician and the foreign surgeon, scheduling appointments with doctors in the USA for pre-trip diagnostic test and post-trip follow-up checks, transcribing and sending medical records. Some firms also provide medical escort services, which may be a nurse who accompanies the patient from the USA to the foreign hospital or it may be a specially outfitted air-ambulance service. Personal care nurses can be hired through supporting firms such as Homewatch, International, Inc. (http://www.homewatchcaregivers.com), to be with the patient during recuperation in a foreign hotel.

In addition, the DMTFs differ in the nature and the amount of information they provide to patients on their websites. Some provide a great deal of educational information that includes detailed diagrams of treatment procedures popularly sought by medical tourists. Such information is usually provided through links to websites such as WebMD or the NIH's MedLine Plus.

Almost all of the firms in this study mentioned that they use case managers. In many cases, however, these managers are stationed in the USA. A basic level of case management provides a representative in the destination country who will at least provide ground transportation (such as airport pick-up and drop-off) in that country. At a higher level of case management, the foreign case managers may even accompany the patient to doctor's appointments and stay with the patient on the day of surgery or the day after surgery, though at additional cost.

The firms also vary in the kinds of optional services they promote on their websites. Some offer to arrange vacation packages and spa services for the patients in the destination countries. Spa services are those that promote healthy lifestyles, a sense of well-being or stress relief. They can include acupuncture, aromatherapy, beauty care, facials, herbal healing, homeopathy, massage, and yoga. Another common add-on is travel insurance. Insurance against medical complications is not as common, but a few firms do offer it (e.g. Global Surgery Network [http://glo balsurgerynetwork. com/Insurance.htm]) and Medvoy [http://www .medvoy.com/]. Several firms will arrange financing through third parties (e.g. IndUS Health [http:// www.indushealth. com/financing_programs.aspx] and Global Med Network [http://www.globalmednetwork.com/html/financing.html]). Financing options can include medical loans or even flexible payment options linked to retirements.

\section{Methodology \\ Data}

To compare the attributes of domestic medical tourism facilitators (DMTFs), firms were identified by using Google and Yahoo! to search for 
phrases related to medical tourism or health tourism during December 2009 and January 2010. Only firms which help medical tourists find treatment abroad and which had their head office in the USA were included; firms that did not refer patients for some kind of surgery were excluded. Thus, firms that catered only to travelers who sought spa services or wellness services were excluded. In the end, 49 DMTFs were identified (see Appendix A). At the time of data collection, three of these firms no longer have a presence on the internet and presumably are no longer engaged in medical tourism. Thus, they were also excluded from this study.

The firms' websites were analyzed for information about the attributes and indicators discussed in the previous section. As a result, 18 variables were derived from the attributes advertised on the firms' websites. They reflect the choices the firms make regarding the services they offer to consumers. In some cases, missing information was filled in from published reports and news items about the firms. The 18 variables used in the analysis and the criteria that were employed to collect them are as follows:

- Number of countries to which the firm refers patients.

- Number of hospitals in foreign countries to which the firm refers patients.

- Medical information - the extent of treatmentrelated information offered by the firm.

- Medical - the firm refers patients for medical surgery (includes bariatric surgery but not eye surgery such as Lasik).

- Dental - the firm refers patients for dental surgery.

- JCI accreditation - the firm only refers patients to facilities that are JCI accredited or ISO 9000 certified.

- Partnerships - the firm identifies a partnership with an employer or insurer by name on its website.

- MDs on staff - the firm has at least one MD in its top-level management.

- Medical escorts - the firm advertises that it provides medical escort services.

- Pre- and post-care - the firm mentions that it will facilitate communications between the foreign physician and the patient's doctor in the USA before and after the trip.

- Financing availability - the firm offers to arrange financing for the surgery and the trip.
- Vacation option - the firm advertises that it will arrange vacation packages in the foreign country.

- Insurance option - the type of insurance offered by the firm.

- Cosmetic/Plastic - the firm arranges cosmetic or plastic surgery services for patients.

- Hospitals named - the firm identifies the hospitals it uses.

- $B B B$ membership - the firm advertises that it is a member of the Better Business Bureau.

- Case management - the firm offers a higher level of case management.

- Spa option - the firm will arrange nonmedical spa or wellness services.

Unless noted otherwise, the variables above are dummy variables having the value of one if the feature was present and zero otherwise. Number of countries coded the number of countries into five categories: $\{1\},\{2$ or 3$\},\{4$ or 5$\},\{6$ to 9$\}$, and $\{10$ or more $\}$. These categories were coded 1 through 5, respectively. This scheme assigns roughly equal numbers of DMTFs to each category, except that the first category has more than the others. Number of hospitals were grouped into five categories whose counts were all between 8 and 10: $\{1$ or 2$\},\{3,4$, or 5$\},\{6$ to 10$\},\{11$ to $18\}$, and $\{19$ or more $\}$. These categories were coded 1 through 5 , respectively. In some cases, missing values were filled in by assuming that there was only one hospital per country; so the number is really the minimum possible in these cases. Medical information has three possible values: 2 if the firm's website had extensive medical information, or links to other websites (such as Web MD or the NIH's Medline Plus); 1 if the website had minimal medical information about the procedures; or 0 if the website simply described the patient's experience during the procedure (e.g. in the form of patient's testimonials on the websites) or did not describe the procedures at all. Insurance option has the value of 0 if the DMTF does not offer any insurance to its clients, 1 if it offers only travel insurance, and 2 if it offers insurance against medical complications.

\section{Procedures}

We first used principal-components analysis to find common themes among the variables. The second step was to find similarities among the firms' websites by applying hierarchical cluster analysis to the resulting components from the 
first step. The results will be described in the next section.

\section{Results}

Principal-components analysis distilled the 18 variables to a smaller set of components. The purpose of this was to find patterns in the characteristics of the DMTFs. A principal-components analysis of all 18 variables and 46 DMTFs resulted in a Kaiser-Meyer-Olkin (KMO) statistic of 0.459 , indicating that a number of these variables did not share common factors with the others. The KMO measure of sampling adequacy and the anti-image matrix were used to successively eliminate five variables, namely Cosmetic/ Plastic, Hospitals named, BBB membership, Case management, and Spa option. The remaining 13 variables yielded a KMO statistic of 0.606 , which indicates a 'mediocre' but acceptable factor structure (Hair et al., 2006: 114). Furthermore, Bartlett's test of sphericity yielded a statistic of $133.187(p<0.0005)$, again indicating that there is a common factor structure among the variables.

Although Kaiser's criterion and the scree plot diagram implied that four components could be extracted, using only three resulted in components that could be more easily interpreted. Furthermore, Kaiser's criterion and the scree plot tend to overestimate the number of components when many of the variables are dichotomous. After VARIMAX rotation, the three components (and the proportions of the variance explained by them), ranked in their order of importance, were: (1) selection focus (18\%), (2) physician focus (16.5\%), and (3) tourism focus (14.6\%) (see Table 4). For each of the three components, a subset of variables was defined by selecting the variables that had loadings greater than 0.4 for that component. The selection-focus component reflects a strategy of providing a broad array of country and hospital options to consumers (see Figure 2). The physician-focus component reflects features that a physician would be more likely to consider important, such as MDs on the management staff of the DMTF, hospital accreditation, and facilitating pre- and post-care communication between doctors. Finally, the tourism focus component reflects a travel-agent's approach, such as emphasizing vacation, dental, and cosmetic surgery packages along with the medical procedures, and a lack of partnerships with insurance companies or employers. Cronbach's alphas for these groups were all greater than 0.5 , indicating that the components did have something in common. The measures of sampling adequacy suggest that the insurance option variable was correlated with the components. However, it did not have a loading above 0.4 with any of the components, and it was therefore not included in any of the three groups of variables.

A cluster analysis was performed next on the sample of 46 firms using the three components derived from component analysis as the clustering criteria. Based on the dendrogram using average linkage (between groups), a six-cluster solution was chosen (see Figure 3). The following describes each of the six distinct clusters and its corresponding characteristics.

The clusters were first divided into two sets: three clusters had high physician-focus scores (clusters 1, 2, and 3), and three that did not (clusters 4,5 , and 6).

Cluster 1: Selection and physician focused firms. Four firms (9\%) make up this cluster. It comprises firms who are consumer-centric in terms of greater choice of destination countries and hospitals, and services that are influenced by physicians. These firms had the highest selectionfocus score and the second highest physician focus, but they scored slightly below average on tourism focus. All of the firms in this cluster were in the highest quintile of the number of countries variable $(p<0.0005)$. These firms were also more likely than other clusters to have MDs in management positions $(p=0.037)$.

Cluster 2: Physician-influenced, tourism-focused firms. This cluster is composed of 5 or $11 \%$ out of the 46 firms. They are characterized by their highest scores in both physician-focus and tourism-focus among all six clusters. They invariably place the highest values on physician-focused services such as pre- and post-care, exclusively using JCI or ISO accredited hospitals (4 of the 5 had this, $p=0.013$ ), MD on staff ( 4 of the 5 had this, $p=0.009$ ), and medical escort services. Similarly, they place the highest emphasis on tourismfocused variables such as the referral to dental treatments and offering of vacation options.

Cluster 3: Physician-influenced without tourismfocused firms. This cluster contains 4 or $9 \%$ of the total number of firms. While they had the third highest physician-focus score and it is average on selection-focus, it is noteworthy for its very low tourism score, the lowest among the six clusters. Thus, it is not surprising that all four firms represented in this cluster do not offer any 
Table 4. Principal component analysis: component loadings

\begin{tabular}{lccc}
\hline & \multicolumn{3}{c}{ Component } \\
\cline { 2 - 4 } Variable & Selection Focus & Physician Focus & Tourism Focus \\
\hline Number of Hospitals & 0.864 & \\
Number of Countries & 0.857 & \\
Medical & 0.614 & \\
Medical Information & 0.419 & & \\
Pre- and Post-Care & & 0.676 & \\
JCl Accreditation & & 0.642 & \\
MDs on Staff & & 0.549 & \\
Financing Availability & & 0.543 & 0.740 \\
Medical Escorts & & 0.453 & 0.743 \\
Partnerships & & 0.400 & 0.651 \\
Vacation Option & & & 1.547 \\
Dental & & & 14.6 \\
Insurance Option & 2.823 & 2.013 & 0.571 \\
Eigenvalue & 18.0 & 16.5 & \\
Percentage of variation explained & 0.672 & 0.560 & \\
Cronbach's alphas & & & \\
\hline
\end{tabular}

Notes:

I. Principal-component loadings after VARIMAX rotation.

2. We ignored loadings less than 0.4. One variable, insurance option, had loadings of 0.380 and 0.347 for physician focus and tourism focus, respectively, and was thus ignored.

vacation options and all but one firm do not offer any dental treatments.

Clusters 4: Narrowly focused small firms. This cluster contains 12 or $26.1 \%$ of the 46 firms. They score below average on selection focus and physician focus but are average on tourism focus. In fact, this cluster has the lowest score on physician-influenced variables among all six clusters. Seventy-five percent of these firms are narrowly focused on hospitals in a single country, while the remainder deals with only two countries $(p<0.0005)$. None of the firms in this cluster had MDs in management positions ( $p=$ $0.024)$. Several of the firms include their destination countries in their companies' names. Several of the street addresses for these firms turn out to be private residences, and in one case a real estate agent and a granite supply company having the same owner are listed at the same address. One of the 12 firms in this cluster has lost its website and appears to be out of business.

Cluster 5: Cosmetics-focus, multiple-destination firms. This cluster consists of 19 or $41.3 \%$ of the total number of firms. This is the largest of the six clusters. Among all the clusters, it scores the second highest on both selection and tourism focuses, but scores second lowest on physician focus. The number of countries used by these firms ranges from 3 to 44 . Eighty-nine percent of the firms in this cluster provide both dental and cosmetic/plastic surgeries. Seventy-four percent offer vacation options. Firms in this group were more likely than other firms to provide medical information on the website $(p=0.005)$, less likely to facilitate pre-or post-care communication ( $p=0.036)$, and none of them identified partnerships with employers or insurance companies $(p=0.047)$.

Cluster 6: Cosmetic-focus, single-destination firms. This cluster contains only 2 (4\%) of the 46 firms in the sample. It is tempting to call these outliers, but they have similarities. Although they have the lowest emphasis on selection focus among all the clusters, they score average on physician and tourism focuses. The low selection focus is reflected in the fact that each uses only one country and the fact that neither of these firms offers medical treatments, emphasizing dental and cosmetic/plastic surgeries instead.

\section{Discussion}

\section{Limitations and research extensions}

This study has been limited by the quantity and quality of the data available. The sample size is somewhat small. The present study started by identifying 49 DMTFs, but only 46 of these firms yielded complete information. One direction for further research is to gather similar data from 


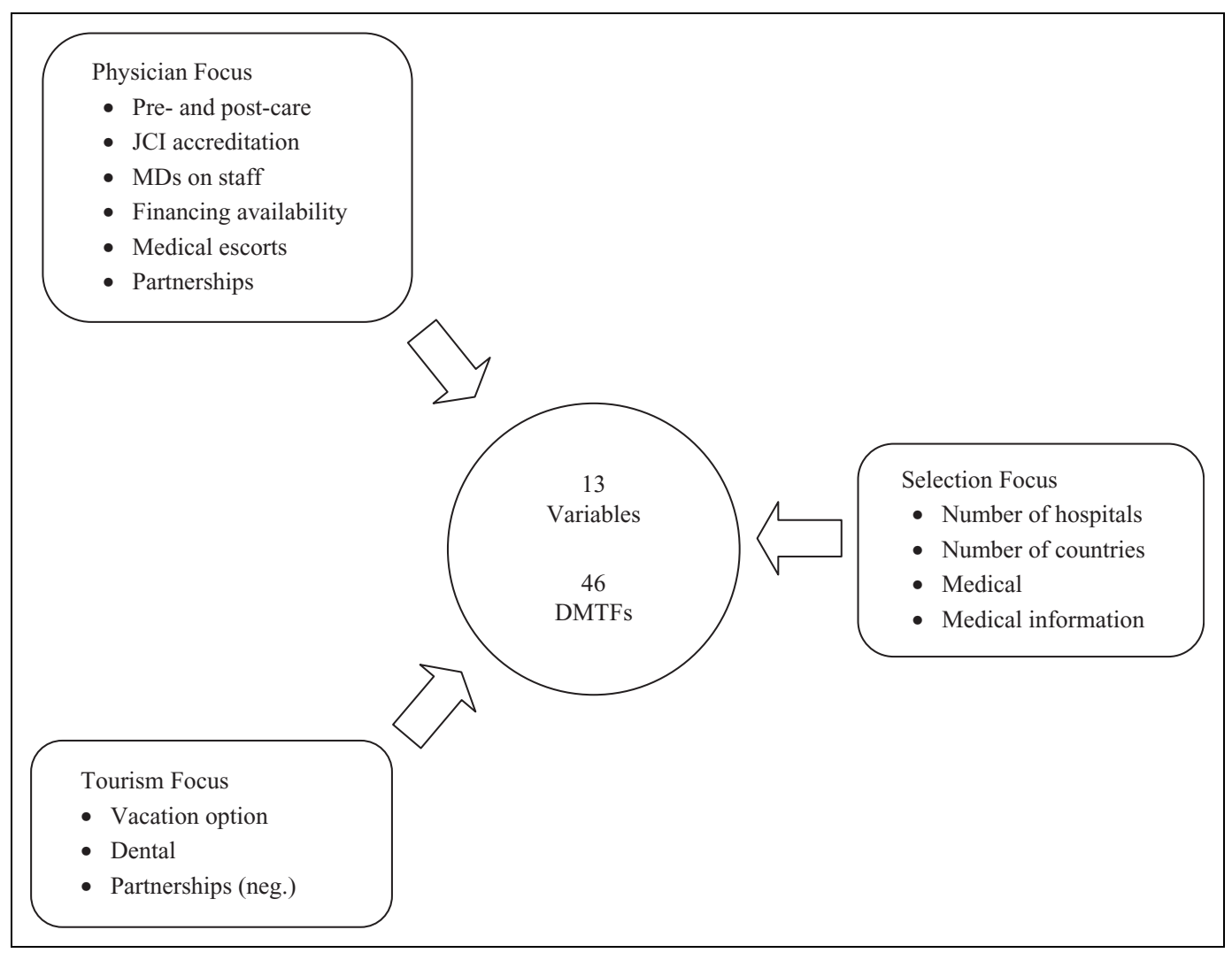

Figure 2. Principal Components and their Variables

foreign MTFs. This would allow comparison of US MTFs with the foreign MTFs, as well as increasing the sample size and thus the robustness of the findings of this study.

This study relied on the firms' websites for most of the data collected. Some assumptions were made, for example, if a firm's website did not say that it had an MD on the firm's management it was assumed that there was not. Thus, this study is more an analysis of the way the firms present their companies' services to the consumers on the internet. Ideally, a survey of the firms with questionnaires would allow better collection of data, along with other kinds of information were not available from the firms' websites directly. For instance, the number of years that firms had been in existence, as well as the prior experience of the management team in industries relating to healthcare, may have an impact on the firms' behavior, but this information was not available on many of the firms' websites. Gathering additional data from interviews with the firms would also strengthen such a study.

As a new and evolving industry, many changes are taking place in this industry. Although opportunities abound in the DMTF market, firms which enter the industry without a clear business model, including differentiation strategies, will probably end up making economic losses and exiting the market. In the first few months of our survey of DMTF websites, three of the 49 firms on the original list left the industry. Furthermore, three new US firms entered the industry. Such turn-over is typical of a monopolistically competitive industry. It will be interesting to study the development of the industry over time, observing the number of firms, the attributes of firms that survive, and whether trends to standardize the services develop.

\section{Results in context}

This article has demonstrated that firms differentiate themselves from each other, and the assumption has been that the differences in part reflect the different strengths of the firms' entrepreneurs. However, it has not addressed the question of why the observed clusters exist. It might be that there are only a few types of entrepreneurs, such as physicians or travel agents. Alternatively, clusters could result from 


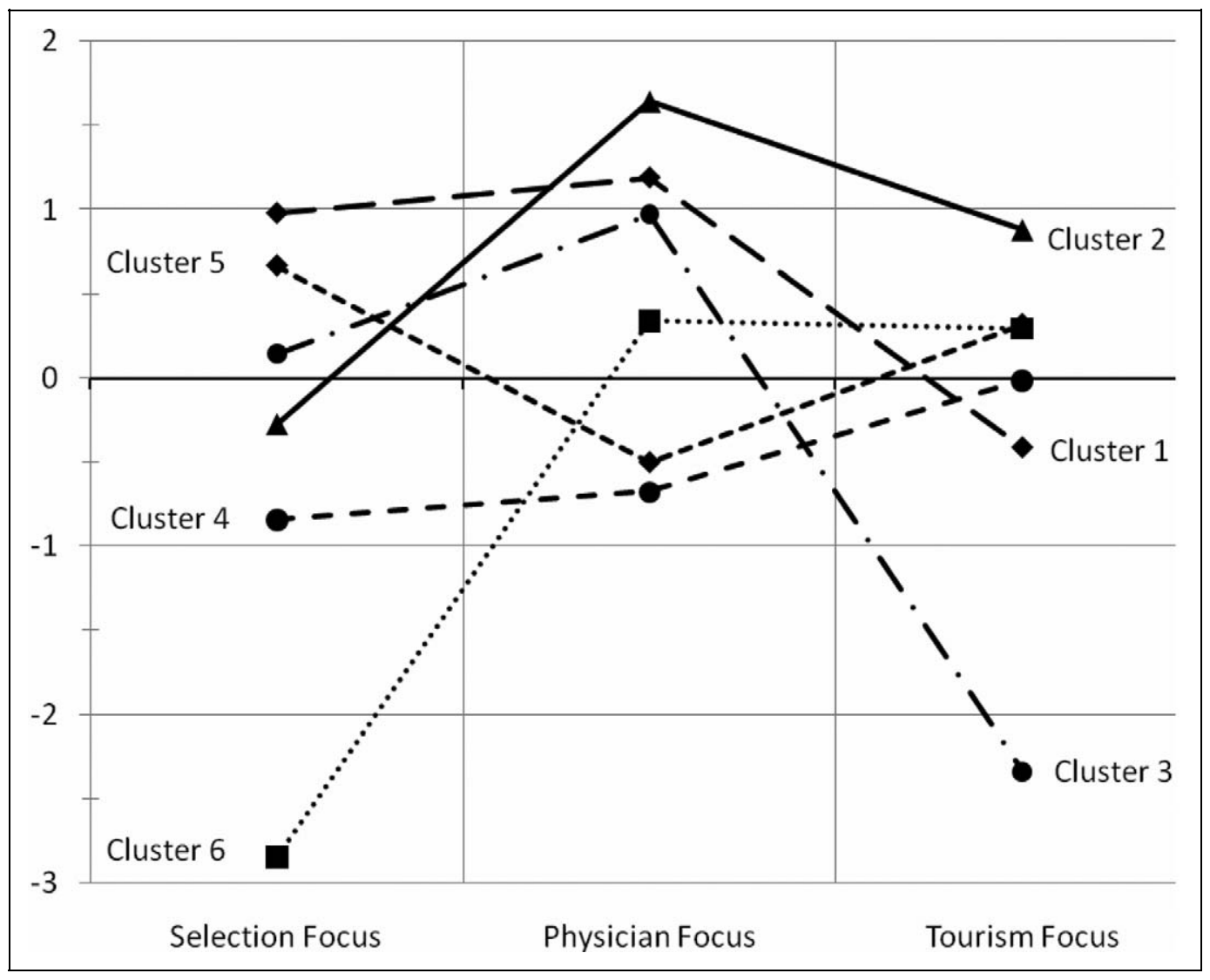

Figure 3. Cluster Profiles of Domestic Medical Tourism Facilitators

economies of scope in the services that the firms provide, or from a small number of distinct management perspectives. It would be advantageous for a DMTF to pattern itself after one of these clusters if the cluster represents a type of firm that is efficient because of economies of scope. On the other hand, these clusters could be the result of firms finding patterns that appeal to consumers. An example of this type of pattern might be cluster 6 , which caters to consumers who seek cosmetic or plastic surgery.

While it is true that the selection-focus component emphasizes information-intensive features such as a long list of country and hospital choices, and a large array of medical procedures, all backed by gigabytes of medical information and databases, consumers can face information overload, not knowing which one to choose from. After all, a potential consumer usually approaches a DMTF with a need for a specific medical procedure and, in some cases, he may already have a particular country destination in mind. In choosing a DMTF, the physician-focus component along with its 'quality indicator' variables (pre- and post-care, exclusively JCI-accredited hospitals, MDs on staff, strategic partnerships, medical escorts) are among the key differentiating features consumers should be seeking. These features tend to stress the quality and safety aspects of the 'medical' procedure in the context of medical tourism. On the other hand, the tourism-focus component which places high values on the vacation option and cosmetic surgeries (which include most dental work) is complementary to those who may wish to relax and recuperate in the destination country, after undergoing an elective or nonelective procedure. In this regard, the tourismfocus component and its related attributes tend to emphasize the 'tourism' or 'leisure' aspect of medical tourism, which may be necessary but they do not independently constitute a sufficient criterion for consumers to choose a DMTF.

For these reasons, those DMTFs classified under clusters which are low in physician focus (clusters 4 and 5 or $67 \%$ of firms in our study) may wish to: (1) strengthen their coordinating efforts in pre- and post-care services; (2) conduct research and visit the prospective hospitals to observe their standards of health and safety if 
resources allow, before intensifying their networking with JCI-accredited or US affiliated hospitals - it is better to start with a few reputable ones than two dozen clinics of low or unknown quality; (3) contract with a US-board certified MD initially, with the goal of recruiting one on staff eventually; (4) initiate partnerships with domestic employers and insurance companies start with a small employer or an insurance broker firm and begin to establish track records; (5) outsource services or integrate supporting service firms such as medical escort companies and software firms that provide information-technology solutions to healthcare management problems, to take advantage of economies of scope.

Those firms which were classified in clusters which are already high on physician focus but low on tourism focus (clusters 1 and 3 or $17 \%$ of firms in this study) may wish to cooperate or integrate with travel agencies to capitalize on the latter's expertise in getting better rates on airfare, hotel accommodation, vacation packages along with foreign case management. The postoperative care of a potential consumer can then be arranged in a luxury hotel, accompanied perhaps by a daily visit by a professional nurse. A natural extension to such economies of scope would be to negotiate some management contracts eventually with established hoteliers, international airlines, and even with pharmaceutical suppliers. Though such partnerships have been formed mostly among foreign healthcare providers such as Plenitas (an Argentinean medical group) with Sheraton hotel chains, and Bumrungrad of Thailand with Thai Airways, an established DMTF can essentially do the same.

In addition, this study shows that DMTFs should perform customer profiling to identify their target markets as well as develop their niche services. For example, one firm, India-America Group Solutions, has created a second website under the name of Boomer Health Travel which is aimed at a different type of consumer than its main website is. As an example of a niche service, US Christians visiting the holy land could be one target consumer group that could be induced to receive medical tourism services at accredited hospitals in Israel, Jordan or Turkey. The DMTFs can use such niche services to develop their branding strategies.

\section{Conclusion}

This article is among the first quantitative research on medical tourism facilitators. It studied the market for DMTFs using a principal component analysis and cluster profiling. It was able to classify these firms into six profiles based on their differentiation strategies, and respective recommendations are offered for firms in various clusters.

The DMTF industry in the USA is currently not regulated by any organization. The fact that it is not difficult to enter the DMTF market due to low entry barriers should be a cause for concern to consumers. It is easy to set up an impressive website with a toll free number, network with some 50 FHPs over email, yet not have any medical personnel on staff to wade through medical records and regulations in other countries, not to mention giving medical advice to potential consumers. Consumers no doubt will benefit from the variety of services offered by this industry, but they will also need to be wary of the possibility that the firm they use may disappear before all of the expected services have been provided. One of the firms that failed had an impressive website, so it will be difficult for consumers to tell which firms are sound and which are not.

Health professionals' associations are just beginning to take stances on medical tourism. Although the American Medical Association (AMA) has a recent position paper (American Medical Association, 2008) that tolerates medical tourism, medical tourism may still be seen as a threat to the domestic medical profession. The AMA paper emphasizes that treatment abroad must be voluntary and that consumers must be fully informed of their risks. Both the American Dental Association (ADA) and the American Society of Plastic Surgeons (ASPS) have also issued statements of caution.

Four recent trends will pose challenges to the DMTFs as they sell their services: First, as the public becomes more knowledgeable about medical tourism and foreign healthcare providers (FHPs), more consumers will seek treatment directly from the FHPs (via Mode 1 in Figure 1). Second, due to escalating healthcare costs, US employers and insurance companies are stepping up their efforts in promoting medical tourism, some of which will be arranged through their direct relations with FHPs (via Mode 3). For example, Blue Shield of California has created a 'Baja network' of three Mexican hospitals, California's HealthNet has created 'Salud con HealthNet' which includes eight Mexican hospitals (MCOL, 2005), and a Blue Cross-Blue Shield unit recently signed a deal with Parkway Health, a group of hospitals in Singapore 
(Rogers, 2008). Third, the 2010 Patient Protection and Affordable Care Act, recently enacted in the USA, is expected to create pressure for DICs and DEs to move toward a more transparent international payment system and better pre- and postcare coordination. If this occurs, there will be an increasing trend of partnerships between domestic healthcare providers (DHP) and FHPs (via Mode 4). And such partnerships will no doubt create new challenges related to consumers' confidentiality, security, sharing of clinical data internationally, and continuity of care (Vitalis and Milton, 2009). Fourth, in an effort to attract more consumers from Europe and North America, more FHPs are developing international patient departments which perform many of the functions of DMTFs. These trends, by escalating the growth of the flow of consumers through the other three modes, and in some cases bypassing the middleman, will serve as threats to the DMTF industry (Mode 2). However, over time, the DMTFs may still find new ways to differentiate their products and services through advertising, trademarks, brand names, developing potential niche markets, and even designing innovative business processes. These efforts may cause the demand for DMTFs' services to increase. It will be interesting to see which trend will persist in the long run.

\section{Funding}

The authors are grateful for a research-assistance grant from the University of North Carolina at Pembroke's School of Business and for the assistance of M. Chandler Bennett in data collection.

\section{References}

AMA-OMSS (2007) Medical travel outside the U.S. OMSS Governing Council Report B, June.

American Medical Association (2008) New AMA guidelines on medical tourism. Available at: http://www.ama-assn.org/ama1/pub/upload/mm/ 31/medicaltourism.pdf

Baliga H (2006) Medical tourism is the new wave of outsourcing from India. India Daily. Available at: http://indiadaily.com/editorial/14858.asp

Berkowitz EN and Flexner WA (1981) The market for health care services: is there a non-traditional customer? Journal of Health Care Marketing 1(1): 25-34.

Bies W and Zacharia L (2007) Medical tourism: outsourcing surgery. Mathematical and Computer Modelling 46: 1144-1159.

Birch DW, Vu L, Karmali S, Stoklossa CJ and Sharma AM (2010) Medical tourism in bariatric surgery. The American Journal of Surgery 199(5): 604-608.

Bookman M and Bookman K (2007) Medical Tourism in Developing Countries. New York: Palgrave MacMillan.

Brady C (2007) Offshore gambling: medical outsourcing versus ERISA's fiduciary duty requirement. Washington Lee Law Review 64(3): 10731114.

Bramstedt KA (2006) Supporting organ transplantation in non-resident aliens within limits. Ethics and Medicine 22(2): 75-81.

Bramstedt KA and Xu J (2007) Checklist: passport, plane ticket, organ transplant. American Journal of Transplantation 7(7): 1698-1701.

Canterbury R, Walters, Eldridge, Schadler, Martin, Ellem, Staggers, Miller, Evans and DeLong (2007) House Bill 2841: Establishing a system to reduce the cost of medical care paid by the Public Employees Insurance Agency. Introduced in the West Virginia House on 5 February.

Carabello L (2008) A medical tourism primer for U.S. physicians. Medical Practice Management March/ April: 291-294.

Carrera PM and Bridges JFP (2006) Globalization and healthcare: understanding health and medical tourism. Expert Review of Pharmacoeconomics Outcomes Research 6(4): 447-454.

Chinai R and Goswami R (2007) Medical visas mark growth of Indian medical tourism. Bulletin of the World Health Organization 85(3): 164-165.

Connell J (2006) Medical tourism: sea, sun, sand and . . . surgery. Tourism Management 27: 1093-1100.

Deloitte LLP (2008) Medical tourism: consumers in search of value. Available at: http://www.deloitte. $\mathrm{com} / \mathrm{dtt} / \mathrm{cda} / \mathrm{doc} /$ content/ si_Medical_tourism\%281\%29.pdf

Deloitte LLP (2009) Medical tourism: updates and implications. Available at: http:/www.deloitte.com/ assets/Dcom-Greece/Local\%20Assets/Documents/ Attachments/Health/Medical_tourism09.pdf

Demicco FJ and Cetron M (2006) Club medic. Asia Pacific Biotech News 10(10): 527-531.

DeNavas-Walt C, Proctor BD and Smith JC (2009) Income, Poverty, and Health Insurance Coverage in the United States: 2008. Current Population Reports: Consumer Income series. Report No. P60-236 (RV). U.S. Census Bureau. Washington, DC: U.S. Government Printing Office.

Dhariwal R (2005) Tourists arrivals in India: how important are domestic disorders? Tourism Economics 11(2): 185-205.

Ellem D, Proudfoot, Kessler, Hrutkay, Guthrie, Moore, Sobonya, Burdiss, Miley, Tabb and Pino 
(2008) House Bill 4711. Originating in the Committee on the Judiciary, West Virginia.

Fernandez LS, Byard D, Lin CC, Benson S and Barbera JA (2002) Frail elderly as disaster victims: emergency management strategies. Prehospital and Disaster Medicine 17(2): 67-74.

Forgione DA and Smith PC (2007) Medical tourism and its impact on the US health care system. Journal of Health Care Finance 34(1): 27-35.

Fried B and Harris D (2007) Managing healthcare services in the global marketplace. Frontiers of Health Services Management 24(2): 3-18.

Gahlinger P (2008) The Medical Tourism Travel Guide: Your Complete Reference to Top-Quality, Low-Cost Dental, Cosmetic, Medical Care \& Surgery Overseas. North Branch, MN: Sunrise River Press.

Gan L and Frederick J (2011) Consumers' attitudes toward medical tourism. Available at http://papers. ssrn.com/sol3/papers.cfm?abstract_id=1837062.

Glinos IA, Baeten R and Maarse H (2010) Purchasing health services abroad: practices of cross-border contracting and patient mobility in six European countries. Health Policy 95(2-3): 103-112.

H\&HN (2004) Competition circling the globe. Available at: www.hhnmag.com

Hazarika I (2010) Medical tourism: its potential impact on the health workforce and health systems in India. Health Policy and Planning 25(3): 248-251.

Henderson JC (2004) Paradigm shifts: national tourism organizations and education and healthcare tourism. The case of Singapore. Tourism and Hospitality Research 5(2): 170-180.

Herrick DM (2007) Medical tourism: global competition in health care. National Center for Policy Analysis, Dallas, TX, Report No. 304, November. Available at: http://www.ncpa.org/pub/st/st304

Higgins LA (2007) Medical tourism takes off, but not without debate. Managed Care. Available at: http://www.managedcaremag.com/archives/0704/ 0704.travel.html

Horowitz MD (2008) Why is offshore medical care inexpensive? (Part 1 of 3). This Week in Medical Travel Today 1(2). Available at: http://www .Medicaltraveltoday.com/MTTE-01-02.html

Horowitz MD and Rosensweig JA (2007) Medical tourism - health care in the global economy. The Physician Executive 33(6): 24-30.

Horowitz MD and Rosensweig JA (2008) Medical tourism vs. traditional international medical travel: a tale of two models. International Medical Travel Journal 3: 30-33.

Huan TC, Beaman J and Shelby L (2004) No escape natural disaster - mitigating impacts on tourism. Annals of Tourism Research 31(2): 255-273.
Jones JW and McCullough LB (2007) What to do when a patient's international care goes south? Journal of Vascular Surgery 46(5): 1077-1079.

Lane PM and Linquist JD (1988) Hospital choice: a summary of the key empirical and hypothetical findings of the 1980s. Journal of Health Care Marketing 8: 5-20.

Lunt N and Carrera P (2010) Medical tourism: assessing the evidence on treatment abroad. Maturitas 66(1): 27-32.

McLean TR (2007) Commentary: the industrialization of medical tourism and the Blue Ridge Paper claim. Journal of Controversial Medical Claims 14(1): 18-19.

Marlowe J and Sullivan P (2007) Medical tourism: the ultimate outsourcing. Human Resource Planning 30(2): 8-10.

Mattoo A and Rathindran R (2006) How health insurance inhibits trade in health care. Health Affairs 25(20): 358-367.

MCOL (2005) Mexican health care for Americans. MCOL Weekend, 22 October. Available at: http:// www.mcareol.com/mcolfree/mcolfre1/mcolfre2/ monthly1105.pdf

Milstein A and Smith M (2006) America's new refugees - seeking affordable surgery offshore. The New England Journal of Medicine 355(16): 1637-1640.

Mirrer-Singer P (2007) Medical malpractice overseas: the legal uncertainty surrounding medical tourism. Law and Contemporary Problems 70(2): 211-232.

Palvia S (2007) Global outsourcing of IT and IT enabled services: a relationship framework and a two stage model for selecting a vendor. In Palvia P, Palvia SCJ and Harris AL (eds.) Managing Global Information Technology: Strategies and Challenges. Marietta, GA: Ivy League Publishing, 433-458.

Rodighiero D, Ellis and Hrutkay (2008) House Bill 4359. Committee on Health and Human Resources then the Judiciary, West Virginia.

Rogers M (2008) Medical tourism: agents have a potential gold mine in booking U.S. citizens into hospitals abroad. Travel Agent, 18 August, p. 61.

Rosenthal J (2009) Medical tourism takes off. National Geographic Traveler 26(4): 10-16.

Seddighi H, Nuttall M and Theocharous A (2001) Does cultural background of tourists influence the destination choice? An empirical study with special reference to political instability. Tourism Management 22(2): 181-191.

Smith PC and Forgione DA (2008) Global outsourcing of healthcare: a medical tourism decision model. Journal of Information Technology Case and Application Research 9(3): 19-30. 
Swalm S and Lundberg (2007) House Bill 1143: a bill for an act concerning the option of a covered state employee under a self-insured group benefit plan to obtain medical care in an accredited foreign health care facility. Introduced in the Colorado House on 1 February.

Turner L (2007) First world health care at third world prices: globalization, bioethics and medical tourism. BioSocieties 2: 303-325.

Uysal M and Crompton JL (1984) Determinants of demand for international tourist flows to Turkey. Tourism Management 5: 288-297.

Vequist DG and Valdez E (2008) Medical tourism economic report: Monterrey, Mexico. Medical Tourism Magazine 4: 21.

Vijaya RM (2010) Medical tourism: revenue generation or international transfer of healthcare problems? Journal of Economic Issues 44(1): 53-70.

Vitalis JE and Milton GA (2009) Medical travel Threat or opportunity for U.S. providers? It depends on your perspective. Journal of the Center for Health Innovation Winter: 10-13. Available at: http://noblis.com/MissionAreas/HI/private/Documents/ horizons2009.pdf

Woodman J (2008) Patients Beyond Borders (2nd Edition). Chapel Hill, NC: Healthy Travel Media.

Zinkewicz P (2008) Medical tourism on the rise. Rough Notes 151(8): 88. Available at: http:// www.roughnotes.com/rnmagazine/search/life_ health_financial/08_08p088.htm

\section{Appendix A. List of Medical Tourism Facilitators $(n=49)$}

\footnotetext{
1 Aesthetics Abroad

2 Altera Health

3 Boomer Health Travel

4 Bridge Health International

5 Companion Global Healthcare

6 Cosmetic Surgery Travel

7 Cosmetic Vacations

8 Costa Rican Medical Care

9 European Medical Tourist

10 Global Health Affiliates

11 Global Med Network, LLC
}

12 Global Medical Conexion

13 Global Medical Retreats

14 Global Medical Services

15 Global Medical Tours

16 Global Surgery Network

17 Health Travel Guides

18 Healthbase

19 India-America Group Solutions

20 IndUSHealth

21 Med Journeys

22 Med Retreat

23 Med Tours International

24 MedCenTrek

25 Medical Tourism Corporation

26 Medical Tourism International

27 Medical Tourism Partners

28 MediTravels

29 MedTrava

30 MedVoy

31 My Surgical Tourism

32 Navigate Global Health

33 One World Healthcare

34 Passport Medical

35 Patients Without Borders

36 Peru Medical Tours

37 PlacidWay

38 Planet Hospital

39 Premier Med Escape

40 Private Health

41 Quest Med Tourism

42 Satori World Medical

43 Siam Medical Travel

44 Sunshine Medical Tourism

45 Surgery Planet

46 Surgical Trip, LLC

47 TransMed Tourism

48 Veiovis

49 WorldMed Assist

\section{Notes}

1. Boomer Health Travel and India-America Group Solutions are the same company. Since it markets itself differently on the two sites, we treated it as if it were two distinct firms.

2. My Surgical Tourism, One World Healthcare, and Sunshine Medical Tourism were excluded from the study because their websites went offline. 